\title{
Dong Hua: choose a hospital and concentrate on one thing
}

Submitted Aug 11, 2019. Accepted for publication Oct 31, 2019.

doi: $10.21037 / \mathrm{atm} .2019 .11 .14$

View this article at: http://dx.doi.org/10.21037/atm.2019.11.14

Wuxi, a city in the south of Jiangsu Province, is hailed as "the pearl in the Taihu Lake". The city is home to the 43-yearold Affiliated Hospital of Jiangnan University (Wuxi Fourth People's Hospital).

The hospital is known for two reasons: its president Dong Hua and its prestigious Department of Oncology.

Dong Hua has spent some 30 years in the hospital, beginning as a passionate college graduate, becoming the head of a well-reputed department, and eventually rising to be the president and captain of the hospital.

Dong Hua has witnessed the hospital grow in size and strength. Initially, established as a municipal hospital, it has since developed into a tertiary class-A general hospital replete with medical services, medical education, scientific research, disease prevention, and healthcare. Its Department of Oncology has become one of the key medical disciplines in Jiangsu Province.

Time has witnessed the developmental footprints of Dong Hua and the hospital, and they have become a part of each other. To be sure, without each other, Dong Hua and the hospital would never be what they are now (Figure 1).

\section{Childhood}

\section{"Being independent and strong was the most valuable treasure in my childbood."}

Wuxi Fourth People's Hospital was inaugurated in 1976 with 200 beds. The Department of Oncology was also set up at the same time, and it was the first cancer treatment facility in the city. A year later, a 10,611-square-meter inpatient building was put into service.

In that same year, a grade three pupil came to a village $200 \mathrm{~km}$ away to live together with his parents in Yancheng, a northern city in Jiangsu Province. His name was Dong Hua.

The little boy did a lot of housework and farm work for his parents, including feeding domestic animals, picking cotton, and cooking meals. An unforgettable experience took place in a down-pouring summer day. When their geese were running away along a river, Dong Hua braved the heavy rain to bring them back home.

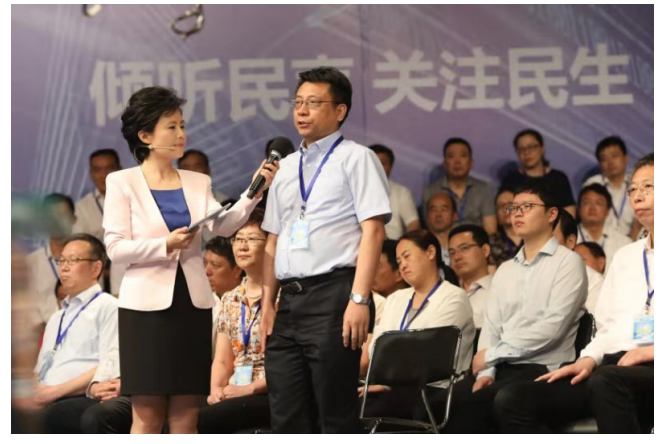

Figure 1 Professor Dong Hua at the Wuxi TV station communicating face-to-face with citizens and responding to the health concerns of the public.

Three years of countryside experience has made Dong Hua stronger and more independent, and these characteristics have proven to be important qualities for how his career has developed.

In the second semester of middle school, Dong Hua returned to study in Wuxi. He only knew the 26 English letters and how to spell some simple words, while his classmates had already learned to use simple sentences in English. He refused to be left behind and took just 6 months to catch up with his classmates. In the second year into middle school, he had become the class's best student in terms of academic performance. A year later he was elected merit student of the city.

In fact, the latecomer had been working hard without the notice of other people. He made a regular and rigorous schedule for himself-get up at 6 o'clock in the morning, then run and read books. He complied with the schedule even on snowy days.

Dong Hua scored very high in the examination and was admitted to the best high school in Wuxi. A few years later he became a student of Nanjing Medical University, and his life has started to turn around after that.

Little did he know that Wuxi Fourth People's Hospital would be a springboard to a momentous career and a means to fulfill his dreams. 


\section{Enlightenment in scientific research}

"When I first learned how to conduct statistics, how to read scientific articles, and how to identify the direction of research ...... I felt like a new world had unfolded in front of me."

In 1989, Wuxi Fourth People's Hospital became a teaching hospital of Soochow Medical College. A year before it was designated as a teaching hospital of Jiangnan University. A cancer research institute was also established in the hospital.

In the same year, Dong Hua graduated from Nanjing Medical University and became an internist at Wuxi Fourth People's Hospital. From then on, the stories between him and the hospital began to unfold.

Five years later, Dong Hua secured an opportunity to pursue a master's degree at Soochow University. "At first I thought I can directly go to study as a postgraduate student, but later I was told that I have to pass the examinations." He had only 1 month to make preparations for three examinations of English, western medicine, and political science. In order to get a better chance, he left the job for half a month to prepare for the tests. He passed all the tests, but the total score was not high enough. Eventually, he became an onthe-job postgraduate and specialized in hematology, one of the best specialties at Soochow University.

Dong Hua said he had no idea what scientific research was about before the start of postgraduate study. Before that, he had been working every day to treat patients' diseases, and he had never thought of why they were sick, how they were stricken by the illness, and why they did or did not recover. Postgraduate study opened a new world for Dong Hua.

Under the guidance of his mentor Xueming Xia and teacher Jianyong Li, Dong Hua learned how to conduct statistics, how to read scientific articles, how to identify the direction of research, and how to carry out experiments on his own.

The two teachers not only had extensive clinical experience but also strong backgrounds in fundamental research. They were keeping abreast of the latest developments in medical science, and their professionalism and code of conduct had a significant impact on Dong Hua. "Prof. Xueming Xia had extensive knowledge and had made significant achievements in diagnosing and treating blood diseases. Dr. Fianyong Li had obtained a doctoral degree a few years prior, and he was also a dedicated teacher."

"His backpack was always filled with academic journals." Dong Hua recalled, noting that when Dr. Li was working on a night shift, he was not reading casual books or sleeping; instead, he was reading literature. He carried out experiments and collected samples. The hospital introduced a new piece of equipment-the flow cytometer-as a new means of measurement. Although the hospital had appointed technical staff and experiment officers, Dr. Li undertook the job of teaching postgraduate students how to operate the flow cytometer.

Dong Hua was deeply impressed by Dr. Li's rigorous attitude toward study. The computer was still not popularized at that time, and Dr. Li could not ask anyone for help because he was only an attending doctor. He gathered samples and prepared patient follow-up information all by himself. He was wholeheartedly devoted to medical science and had paid little attention to everyday food and clothing.

With Dr. Jianyong Li as a role model, Dong Hua was learning to make the rounds of the wards, do experiments, and write academic papers. From what he was seeing and hearing, Dong Hua was trying to summarize his work and draw up theoretic conclusions.

The 3-year postgraduate study was very helpful to improve his scientific thinking. When he found a problem in clinical practice, he would think of what's behind the problem, whether similar problems have happened before, and whether the problem has been discussed or explained by other people in research papers. Gradually, he developed the habit of seeing problems from different perspectives, and the ability to do his job improved rapidly.

During the postgraduate study, Dong Hua made some small achievements in medical research, and published a few research articles about leukemia, like "The clinical and biological significance of megakaryocytic antigen expression in acute myeloid leukemia" in top Chinese journals including the Chinese fournal of Hematology. This was a significant breakthrough for a young doctor working at a municipal hospital.

\section{Discipline building}

\section{"If a discipline remains strong after you retire, it means that you are successful."}

The 3-year postgraduate study had not only enlightened his scientific thinking but also been an important driver for his medical career and for the turnaround of the Department of Oncology at Wuxi Fourth People's Hospital.

After securing a master's degree in 1998, Dong Hua was 
named a candidate for an academic leader position assigned to work at the Department of Oncology. This assignment has closely associated him with cancer research and heralded the rapid development of the department.

Five years of experience in internal medicine had developed his perception into systematic treatment while 3 years of postgraduate study of hematology had connected him to oncology. He was soon qualified for his new job and demonstrated his competence during his assignment.

A year after he joined the Department of Oncology, he was promoted to deputy chief of the department due to outstanding performance. Under the leadership of the department head, Dong Hua worked together with colleagues from the Department of Radiotherapy and Department of Interventional Therapy to file joint applications for "the First Batch of Key Clinical Specialties in Jiangsu Province”. Since the applications involved three departments at the hospital, Dong Hua needed to coordinate and communicate extensively.

Good news came in 2000. The Department of Oncology was named one of "the First Batch of Key Clinical Specialties in Jiangsu Province", and only two hospitals in Wuxi won the accolade. It was a significant progress for the department after it was designated as one of "the First Batch of Key Clinical Specialties in Wuxi City".

In 2001, Dong Hua was appointed head of the department of oncology. At 34 years old, he was the youngest leader of a first-degree department at the hospital.

Dong Hua was grateful to all talent scouts he has met in his life, and was thankful to excellent colleagues who had positive impact on him. When he reached a point where he could also influence others, he was contemplating how to be a good guide.

"If a discipline remains strong after you retire, it means that you are successful." He kept these words of leadership firmly in mind, and has been motivating himself to building and strengthening the discipline. "I bope to build a ladder of talents, and when I hand over the leadership to one of them, the discipline can continue to develop at a relatively bigh level; then I think I would be successful."

From his perspective, the direction of development is crucial to build a discipline, and the direction is built on the basis of a clear understanding of the frontier technologies, on the basis of satisfying local residents' medical demands, and on the basis of the existing work. Staffing and research arrangements can be made to advance the building of the discipline.

In the past two decades, he has been committed to cancer research and treatment and led the team to explore medical technologies and improve the department's research and teaching capacities. Clinical practices, teaching, and research are mutually beneficial and helpful to make the discipline stronger.

Dong Hua set a mandatory rule that young doctors must spend at least 3 months a year in the laboratory to do research work, and during the 3 months they do not take other jobs.

In the process of conducting basic research and building a sound research system, Dong Hua encourages independent innovation, and calls for researchers to identify a specific direction and make constant and concentrated research efforts. "We have to be patient when sitting on a cold bench, and ignore changes in the outside world."

Drug resistance and individualized treatment, said Dong Hua, require constant research to find the best cancer therapy.

Since the end of 1990 s more options for cancer treatment have been developed, such as chemotherapy, immunotherapy, and targeted therapy, along with improved efficacies. However, drug resistance has always been a formidable challenge in the fight against cancer. Dong Hua has been striving to overcome this challenge.

For instance, drug resistance may be associated with several proteins such as p-glycoprotein (PGP), lung resistance-related protein (LRP), and multidrug resistanceassociated protein (MRP). However, we have not seen any practically effective testing methods to evaluate drug resistance. Meanwhile, it is also unclear why a drug-resistant cancer cell will transmit such an ability to another cell and which channels and mechanisms are working.

In 2012, Wuxi Fourth People's Hospital formally became an affiliated hospital of Jiangnan University. Under the leadership of Dong Hua, the hospital's Department of Oncology carried out joint studies with the university's School of Pharmaceutical Sciences to explore answers to the problems related to drug resistance.

Based on the studies on intestinal cancer and breast cancer cell strains, the research team discovered several channels and found that drug-resistant cells transmit drug resistance information to nonresistant cells through vesicles. These studies helped to clarify the drug resistance mechanism of PGP, the transmission channels between drug-resistant cells and drug-sensitive cells, and the testing of blood samples for evaluating drug resistance.

After years of painstaking research, his team developed a tumor multi-drug resistance diagnostic system based on 


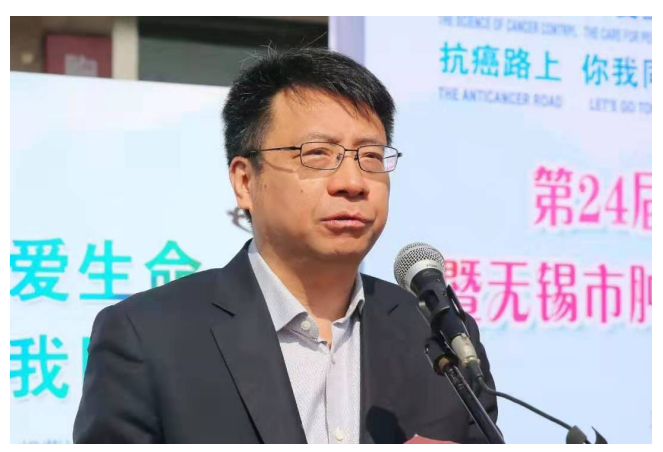

Figure 2 Prof. Dong Hua hosting the launch ceremony of the $24^{\text {th }}$ National Cancer Prevention Week at a Wuxi sub-venue.

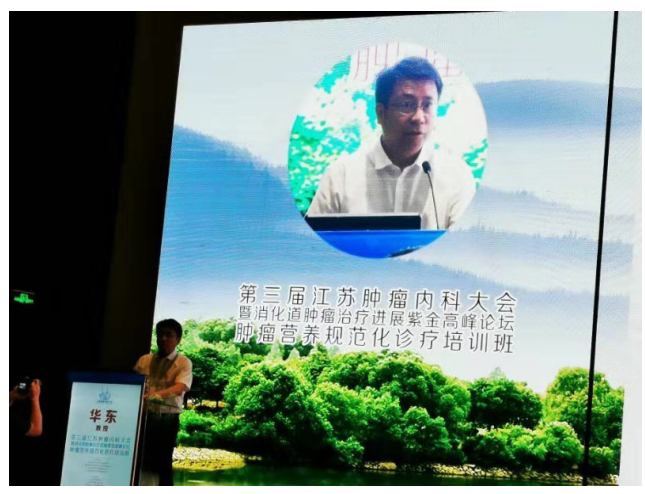

Figure 3 Prof. Dong Hua giving a speech at the $3^{\text {rd }}$ Jiangsu Symposium on Medical Oncology.

the transient receptor potential channel 5 (TrpC5), and the results were published in the Proceedings of the National Academy of Sciences of the United States of America (PNAS) and the Fournal of Biological Chemistry $(\mathcal{F B C})$ and recognized by international peers. Also, his team won the Jiangsu Provincial Scientific and Technological Progress Award (third grade).

"What are the reasons bebind failed cancer treatment? Why do different cancer patients have different prognoses even though they have tumors at the same site and receive the same therapy?" Dong Hua hopes to make breakthroughs in some specific areas and give patients a greater chance at survival.

In light of the heterogeneity of tumors, Dong Hua was among the first doctors in Jiangsu to introduce individualized therapy. Later, he conceived the idea of precise medicine. The two share some similarities and small differences and have become Dong Hua's major research directions.

Through cooperation with the key disciplines in Jiangnan
University, the Department of Oncology has produced a series of influential, competitive, and characteristic research achievements. The main research topics in this department are translational research on the immune micro-environment and drug resistance of gastrointestinal malignancies.

In 2017, the hospital secured approval to build a key discipline of oncology in Jiangsu Province, marking a significant breakthrough for the hospital.

From a specialty to a discipline, this small difference has demonstrated the hospital's shift from a clinical medicinebased hospital to one with balanced emphasis on both clinical practices and scientific research and marked an upgrade of its capabilities in research and talent training. In recent years, the Department of Oncology has undertaken several national and provincial research projects and received multiple awards from Jiangsu and Wuxi for its contributions to scientific and technological progress (Figures 2,3).

\section{The philosophy and art of management}

"Building a bridge when there is a river, taking the initiative to resolve problems, and setting a good example for team members"

There is an old saying: "at the age of 40, people begin to be immune from perplexities". At the age of 40 , people tend to have a stable life and work. For Dong Hua, however, 40 is the start of a new life, as he remains thirsty for knowledge and curious about the unknown world. "Let me have one more journey!" He missed the opportunity to pursue a doctoral degree 7 years ago. Now he has decided to go to the campus again, to recharge, make amends, and do a better job in his work.

The English test for the 2007 doctoral entrance examination was extremely difficult. "After the English test in the morning, about half of examinees did not show up in the afternoon. The test was really difficult, we did not even understand the questions." In the 1984 national college entrance examination, he met with the so-called "most difficult" mathematics test. Fortunately, Dong Hua passed both tests, and became a doctoral candidate.

If postgraduate study was the first milestone in his life, the 4-year doctoral study would be his second milestone. "A master's candidate needs to study the superficial phenomenon of a specific scientific practice, while a doctoral candidate requires deep exploration of the internal mechanisms." Dong Hua said, 


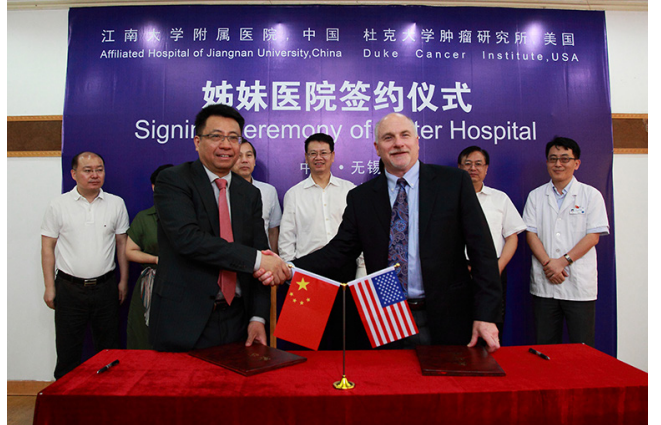

Figure 4 Signing ceremony for friendly cooperation between Affiliated Hospital of Jiangnan University and Duke Cancer Institute.

adding that doctoral study enabled him to oversee the department's construction and development from a larger, broader, and deeper perspective.

In his second year into doctoral study, Dong Hua was appointed vice president of the hospital to oversee research and teaching activities. That meant he would be busy attending doctoral courses, managing the Department of Oncology, and handling the hospital's administrative affairs.

"A doctoral student's scientific thinking is helpful to perform my management duties." In his opinion, management is not only an independent discipline but also associated with disease research.

"During the research management, we should not blindly require each department to get grants from the natural foundations and research programs; rather, we have to provide instructions about how to conduct research and apply for research funding." He reckoned that the transition from a cell experiment to an animal study and then a human trial is a process. Only the translation to clinical application brings tangible benefits to patients.

In 2016, Dong Hua was appointed the party secretary of Wuxi Fourth People's Hospital, and a year later he became president to oversee the hospital's overall development (Figure 4).

Three decades of perseverance has turned Dong Hua from an undergraduate to a doctoral candidate, from a master's supervisor to a doctor's supervisor, from a resident doctor to a senior physician, and from an ordinary doctor to a department chief and a hospital president. He has his own experience and thinking about the advantages and disadvantages of Wuxi Fourth People's Hospital during its development.

Dong Hua and his management team have decided to adjust the hospital's management philosophy, from unrefined management to refined management; from the simple pursuit of quantitative development to the pursuit of quality development; from the goal of bringing in more patients to the path of development driven by core diseases, core technologies, and value-based health-care.

He is good at using philosophical and dialectical thinking to guide his work and to communicate with hospital management. He pointed out that the dialectical materialist view is that all things are universally connected, and this connection exists not only in scientific research but also in management. The management of each specialty cannot be separated from others, so it requires cooperation and coordination. The same rules can be applied to science, sociology, and management.

Dong Hua holds that mid-level cadres should play three roles: building a bridge when there is a river, taking the initiative to resolve problems, and setting a good example for team members. He said mid-level cadres should consider themselves to be working for a first-class hospital in Jiangsu and even across the country, and every team member should be able to work innovatively and independently.

As a person in pursuit of perfection, Dong Hua set high standards not only for the team, but also for himself. When he was a department's chief, he tried to be the best chief; when he is a hospital's president, he also strives to be a good president. He tries to achieve the best outcome for everything.

No matter how busy he is in hospital management, he has never abandoned his roles as a doctor and teacher. After becoming president of the hospital, Dong Hua has continued to teach students, see patients, and make the rounds of the wards. He also serves as the vice chairman of Jiangsu Society of Tumor Chemotherapy and Biotherapy and other professional organizations. Giving lectures, reading books, and reviewing scientific articles, he has remained engaged in oncology and kept abreast of the latest developments in the discipline (Figure 5).

"You have taken managerial roles since 2008, and held positions like the hospital's vice president, Party secretary, and president. So which role are you satisfied with?"

"I'm satisfied with none of them."

"Why?"

"I have not met my original requirements."

During the interview, Dong Hua was resolute, decisive, and without hesitation. After the combination of the Third and Fourth People's Hospitals of Wuxi, the new hospital will be relocated to the Taihu New Town in 2019. Standing 


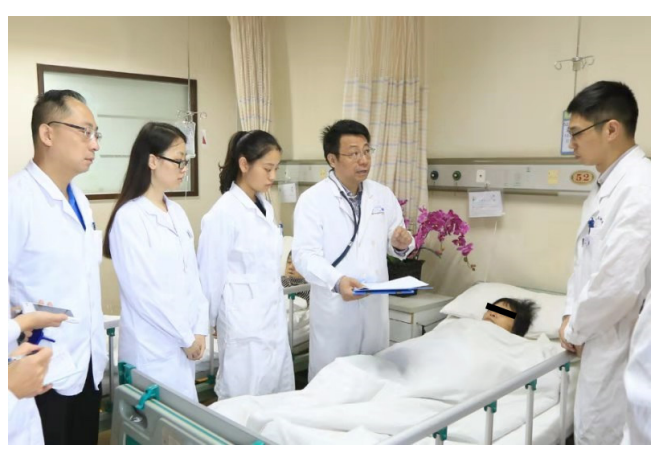

Figure 5 Prof. Dong Hua teaching in daily clinical practice.

at the starting line of a dawning era, Dong Hua will lead the new hospital to strive for the title of the best hospital in Wuxi and one of the top 10 hospitals in Jiangsu Province.

The future is coming, and the road to it is underfoot.

\section{Profile}

Dr. Dong Hua is a chief physician, professor, doctoral tutor, and president \& Party secretary of the Affiliated Hospital of Jiangnan University.

Since graduating from university in 1989 , he has been involved in the clinical management, scientific research, and treating of malignant tumors. He has strong capabilities in the judgment and rescue of complex and difficult cases. He was the winner of many honorable titles including the Jiangsu 333 Talent (the second level), the Key Medical Talent in Jiangsu Province, and the Famous Doctor in Wuxi City. He was also granted the awards including the National Advanced Workers in Health and Family Planning Sector, the Young and Middle-aged Expert with Outstanding Contributions in Jiangsu Province, and the May 1st Labor Medal of Jiangsu Province.

His research focuses on co-stimulatory molecules

Cite this article as: Gao C, Dong J. Dong Hua: choose a hospital and concentrate on one thing. Ann Transl Med 2019;7(22):707. doi: 10.21037/atm.2019.11.14 expressed by tumor and tumor microenvironmental cells, tumor immunity, and tumor drug resistance. The multicenter clinical trial team led by him was invited to give an oral presentation at the World Conference on Lung Cancer (WCLC). He is the principal investigator of one study supported by the National Natural Science Foundation of China and seven provincial and ministerial research projects, with the sum of vertical grants reaching more than 4 million yuan. He has published over $30 \mathrm{SCI}$ articles, some of which were published in top journals including PNAS and $\mathcal{F B C}$. He was the winner of one Jiangsu Science and Technology Progress Award (third grade), eight Jiangsu New Technology Introduction Award, and two Wuxi Science and Technology Progress Award (second grade).

Currently he also serves as the vice chairman of Jiangsu Society of Tumor Chemotherapy and Biotherapy, vice chairman of the Cancer Immunology Committee of Jiangsu Immunology Society, vice chairman of the Cancer Recurrence and Metastasis Committee of Jiangsu AntiCancer Association, executive director of Jiangsu AntiCancer Association, member of the director board of Jiangsu Medical Association, member of the director board of Jiangsu Immunology Society, and member of the Oncology Branch of the Chinese Medical Doctor Association.

\section{Acknowledgments}

None.

\section{Footnote}

Conflicts of Interest: The authors have no conflicts of interest to declare.

(Science Editors: Chen Gao, Jie Dong, ATM, editor@ atmjournal.org) 